\title{
Reliability Centered Maintenance to Determine Priority of Machine Damage Mode
}

\author{
Indah Rizkya ${ }^{1, *}$, Ikhsan Siregar, Khawarita Siregar, Rahim Matondang and Enrico Waldo Henri \\ ${ }^{1}$ Department of Industrial Engineering, Faculty of Engineering, North Sumatera University, Medan - Indonesia
}

\begin{abstract}
High machine downtime results in the production process being disrupted. The average engine breakdown in the sterilizer production is 35.66 hours/month. The corrective maintenance method has not been able to guarantee a smooth production process. This study will plan preventive maintenance activities in order to increase the reliability of production machinery and also maintain the smooth production process. The study was carried out by identifying the damage level of a sterilizer machine with the FMEA method. Based on the result of the FMEA method, maintenance planning of the production machine using the Reliability Centered Maintenance (RCM). FMEA indicates that there are 5 highest risk priority number values, namely the IGBT, Mosfet, bearing bushings, rool former and v-block components. For the maintenance planning using the RCM method, the results obtained were the Total Minimum Downtime (TMD) criteria indicates that the optimum turnover interval of Roll Former, Mosfet, V-Block, IGBT, and Bearing Bushing components is 24 days, 23 days, 25 days, 26 days, and 22 days. The recommendation of the RCM maintenance method has the potential to have a positive impact, namely a decrease in the average critical component downtime of $37,103 \%$ and also an increase in reliability.
\end{abstract}

Keywords: Machine Damage; FMEA; Reliability Centered Maintenance; Downtime Machine.

\section{Introduction}

Over the years, maintenance has been very often undervalued because it was considered to be only costly. So that it only focuses on production activities. Afterward, the real advantage offered by the proper application of maintenance techniques has been understood by ordering an engineering branch for maintenance and by defining the methodology for managing it efficiently, among them RCM (Reliability Centered maintenance) [1].

Reliability Centered Maintenance consists of determining the most effective maintenance approach [2, 3]. Reliability Centered Maintenance (RCM) is a systematic approach to determine plant maintenance requirements and equipment used to optimize preventive maintenance strategies [4]. RCM is one of the most famous and most commonly used devices to preserve the operational efficiency of the steam system. RCM operates by balancing the cost of high corrective care at a programmable (preventative or predictive) cost of polices, taking into account the potential shortening of the "useful life" of the considered items. But it is difficult to choose the appropriate maintenance strategy for each piece of equipment and each mode of failure, for a large amount of equipment and the uncertain factor of the decision of the adherence strategy [5].

Reliability Centered Maintenance is a systematic process used to determine what must be done to ensure that each facility is able to fulfill its function. Reliability
Centered Maintenance leads to a Preventive Maintenance program that can prevent any possible failure modes [6].

Machinery and production equipment are the most important elements in supporting the continued production of a manufacturing company. Scheduled maintenance is needed on production machines in the company because machinery and production equipment are very vulnerable to the damage occurrence. Damage results in delays and disruption of production.

For the continuity of its production process, the company is supported by a quantity of machines and equipment that interacts with each other to achieve optimal productivity. According to Rao in his article entitled Preventive Maintenance Characteristics towards Optimal Maintenance Performance explained that preventive maintenance is an effective approach to improve the reliability and quality of the system and its components. To prevent failures occur, preventive maintenance practices need to be able to show maintenance work. The purpose of maintenance is to extend machine life [7].

Many previous studies have been carried out to overcome machine downtime with RCM as in conventional lathe machine [8], individual sectionforming machines in the glass bottle industry [9], in the automobile industry [10], and others. This study aims to analyze the reliability of the machines, minimize downtime and recommendation a maintenance schedule.

\footnotetext{
* Corresponding author: indahrizkya@gmail.com
} 


\section{Methodology}

The research was conducted at one of the companies in North Sumatera that produce machinery and equipment for palm oil processing plants such as vessels, sterilizers, boilers, storage tanks, and filters, etc. Preventive Maintenance is a scheduled maintenance system of an equipment/ component designed to improve the reliability of a machine and to anticipate all maintenance activities that were not planned before. The object under study is the sterilizer production process. The steps in implementing Reliability Centered Maintenance are as follows [11]:

1. System Selection and Information Collection

When deciding to implement the RCM program at the facility there were two things that were taken into consideration

2. Defining System Limits

3. System Description and Function Block Diagram The system description is needed to find out the components contained in the system and how the components contained in the system operate.

4. System Function and Function Failure

In this section, the analysis process is more focused on the malfunction, equipment failure will be discussed in Failure Mode and Effect Analysis (FMEA).

5. Failure Mode and Effect Analysis (FMEA)

RCM approach is based on the system functional failure analysis using features such as failure modes and effects analysis (FMEA) [6]. FMEA is a method that is used to evaluate the design of various failure modes of the system consisting of component components and analyzing their effects on the system's reliability. The Risk Priority Number (RPN) value is used to determine the highest failure rate. RPN is a relationship between three variables, namely Severity, Occurrence, and Detection.

6. Logic (Decision) Tree Analysis (LTA)

The compilation of Logic Tree Analysis (LTA) aims to give priority to each damage mode, perform a function review, malfunction and the damage mode status is not the same. The critical analysis places each mode of damage into one of four categories, namely evident, safety, outage, and category.

7. Selection of Actions

In this process, determining the right action for certain damage modes. Tasks chosen in preventive maintenance activities must be applicable and effective.

\section{Result and Discussion}

\subsection{Component Categories Based on Logic Tree Analysis (LTA)}

Based on the results of the determination of Logic Tree Analysis (LTA), the failure categories of each machine component can be obtained. The categorization of each component is carried out on the following considerations:
- A Category (Safety problem) components that can cause safety disturbances to operators and the environment. Based on the results of the study, there are no components included in this category.

- B Category (Outage problem) namely components that can cause failure on all parts of the system. The components included in this category are Nozzle, Swirl Baffle, Shield Cup, Coll Feeding, Roll Former, Mosfet, IGBT, Fan, V Block, Scriber, Solonoid Flud, Bearing Bushing

- C Category (Economic problem) components that cannot cause failure on all or part of the system but cause losses to the company due to component functions reduction. Based on the results of the study, there are no components included in this category.

- D Category (Hidden failure) namely components whose function failure is not realized and difficult to detect by the operator because it is hidden from the operator's vision. The components included in this category are Drill Chuck and T-Bolt

From the results of the study, it can be seen that the source of damage to the engine components is outage which can result in total failure in the system or part of the system.

\subsection{FMEA's Analysis}

Based on FMEA analysis in the sterilizer production process, it will be known the causes of component damage and also the effect on the overall system functions and it can be found the effective engine component maintenance solutions. With FMEA analysis, RPN (Risk Priority Number) values can be obtained for each component and maintenance can be focused on the main components that have the highest priority value in the production process system. The terms used in FMEA are different from risk management standards, but the understanding is the same. These terms are:

- Failure is the failure of a process or product

- Severity is the impact arises when a failure occurs

- Occurrence is the probability or frequency of errors

- Detection is the possibility to detect an error will occur or before the impact of the error occurs

- Risk Priority Number-RPN is the result of multiplication of each level of occurrence and detection.

From the results of the damage caused to each machine component, the occurrence, detection, and severity values are obtained.

In the Nozzle part, an occurrence value of 3 is given because the damage rate of the part is 5 times per 7200 hours of usage. The value of detection is 2 because it has a high chance of being detected and the severity value is 7 because it causes a reduction in the main function. In Swirl Baffle, occurrence value is 3 because the part damage is 6 times per 7200 hours of usage, the value of detection is 2 because it has a very high chance of being detected, the severity value of which is 8 caused by losing the main function. 
In part Shield Cup is given an occurrence value of 2 because the damage rate of the part is 4 times per 7200 hours of usage, the value of detection 2 because it has a very high chance to be detected, the severity value of 8 because it causes the loss of the main function. In the Cool Feeding part, the occurrence value 3 is given because the damage rate of the part is 7 times per 7200 hours of usage, the value of detection 3 because it has a high chance of being detected, the severity value 7 because it causes a reduction in the main function.

In the Roll Former section, there is an occurrence value of 4 because the damage to the part is 10 times per 7200 hours of usage, the value of detection 4 is because it has a high enough chance to be detected, the severity value is 10 because it causes the machine failure at all. In Mosfet part, there is an occurrence value of 4 because the damage to the part is 11 times per 7200 hours of usage, the value of detection 6 is because it has a very high chance to be detected, the severity value is 10 because it causes the machine to not function at all.

Occurrence 5 is given in IGBT part because the damage to the part is 15 times per 7200 hours of usage, the value of detection 6 is because it has a very high chance to be detected, and the severity value is 10 because it causes the failure machine. The occurrence 3 value in the Selenoid Valve part is due to the damage to the part 8 times per 7200 hours of usage, the value of detection 3 because it has a high chance of being detected, the severity value 7 because it causes the engine to experience a reduction in the main function. Occurrence 3 is given in Part Fan because the damage to the part is 8 times per 7200 hours of usage, the value of detection 2 is because it has a very high chance to be detected, and the severity value is 8 because it causes the machine to lose its main function.

In the Switching Transformer part, there is an occurrence value of 3 because the damage rate of the part is 9 times per 7200 hours of use, the value of detection 2 because it has a very high chance to be detected, the severity value 7 because it causes the engine to decline. In Drill Chuck part, the occurrence value 3 is given because the damage rate of the part is 8 times per 7200 hours of usage, the value of detection 2 because it has a very high chance to be detected, the severity value 7 because it causes the engine to experience a decline.

In the V-Block part, an occurrence value of 4 is given because the damage rate of the part is 10 times per 7200 hours of usage, the detection value because it has a high chance of being detected, the severity value 9 due to very low opportunities and very difficult to detect. In the Scriber part, the occurrence value is given 3 because the part damage rate is 7 times per 7200 hours of usage, the value of detection 3 because it has a high chance to be detected, the severity value 7 because it causes the engine to experience a decline in the main function.

- In the T-Bolt part, an occurrence value of 3 is given because the damage rate of the part is 6 times per 7200 hours of usage, the value of detection 2 because it has a very high chance to be detected, the severity value 7 because it causes the decline engine.
- In Solonoid part, Fuld is given an occurrence value of 2 because the damage level of the part is 4 times per 7200 hours of usage, the value of detection 2 is because it has a very high chance to be detected, the severity value 7 is because it causes the decline engine.

- In part Bearing Bushings, there is an occurrence value of 4 because the damage to the part is 11 times per 7200 hours of usage, the value of detection 6 is due to a low chance to be detected, the severity value is 10 because it causes the engine failure.

Then the RPN value of each component is obtained. The RPN value of each component can be seen in Table 1.

Table 1. RPN Failure of Engine components

\begin{tabular}{|c|c|c|}
\hline No & Component & RPN \\
\hline 1 & IGBT & $\mathbf{3 0 0}$ \\
\hline 2 & Mosfet & $\mathbf{2 4 0}$ \\
\hline 3 & Bearing Bushing & $\mathbf{2 4 0}$ \\
\hline 4 & Rool Former & $\mathbf{1 6 0}$ \\
\hline 5 & V-Block & $\mathbf{1 0 8}$ \\
\hline 6 & Scriber & 63 \\
\hline 7 & Coll Feeding & 63 \\
\hline 8 & Selenoid Valve & 63 \\
\hline 9 & Swirl Baffle & 48 \\
\hline 10 & Fan & 48 \\
\hline 11 & T-bolt & 42 \\
\hline
\end{tabular}

The results above show that the detection rating determination is done by looking at the effectiveness of the detection method in detecting potential causes of failure. Means by detection methods is a method used to detect potential failures and failure after failure. The method's ability to detect potential failures and failure will determine its rating. The more likely the detection ability is the smaller than the rating. The biggest failure mode that often occurs in each component. The greater the value, the more frequent damage to the component.

\subsection{Maintenance Procedures Based on RCM Action Selection}

The selection of actions is the last stage of the RCM process. From each failure mode a list of possible actions is made and then chooses the most effective action. Based on the previous steps that have been carried out, 9 components are classified as condition directed, 5 components classified as time directed and 2 components classified as finding failure. 


\subsection{Recommendation Component Replacement Schedule}

In testing this pattern of distribution and reliability, researchers used Easy Fit Professional 5.5 software. The results of the recapitulation of distribution tests and their parameters can be seen in Table 2 .

Table 2. Recapitulation of Distribution Test and Determination of Failure Interval Parameters

\begin{tabular}{|c|c|c|}
\hline Component & $\begin{array}{c}\text { Distribution } \\
\text { Pattern }\end{array}$ & \\
\hline Roll Former & Gamma & $\begin{array}{r}\alpha=1,790 ; \\
\beta=19,674\end{array}$ \\
\hline Mosfet & Lognormal & $\begin{array}{r}\sigma=0,503 ; \\
=3,4385\end{array}$ \\
\hline IGBT & Weibull & $\begin{array}{c}\mathrm{a}=2,981 ; \\
\mathrm{b}=24,394\end{array}$ \\
\hline V-Block & Gamma & $\begin{array}{r}\alpha=2,017 ; \\
\beta=19,061\end{array}$ \\
\hline Bearing Bushing & Lognormal & $\begin{array}{r}\sigma=0,605 ; \\
=3,3454\end{array}$ \\
\hline
\end{tabular}

This distribution testing is carried out for the calculation of the total minimum downtime. Then from this stage, Minimum Total Downtime can be obtained to determine the optimum replacement interval obtained from selecting the minimum simulation results in Easy Fit Professional 5.5 software. The results of the recapitulation of the calculation of the Minimum Total Downtime can be seen in Table 3.

Table 3. Calculation Recapitulation of Total Minimum Downtime (TMD).

\begin{tabular}{|c|c|}
\hline Component & $\begin{array}{c}\text { Optimum } \\
\text { Replacement } \\
\text { Interval (day) }\end{array}$ \\
\hline Roll Former & 24 \\
\hline Mosfet & 23 \\
\hline IGBT & 26 \\
\hline V-Block & 25 \\
\hline $\begin{array}{c}\text { Bearing } \\
\text { Bushing }\end{array}$ & 22 \\
\hline
\end{tabular}

The optimum component turnover results are obtained. Each component can be replaced by components based on the results obtained.

\subsection{Comparison of Actual and Recommendation Maintenance System}

Result recapitulation of the actual system downtime and recommendation reduction can be seen in Table 4 .

Table 4. Reduction of Downtime Value

\begin{tabular}{|c|c|c|c|}
\hline Component & $\begin{array}{c}\text { Downtime } \\
\text { Actual }\end{array}$ & $\begin{array}{c}\text { Downtime } \\
\text { Recommenda } \\
\text { tion }\end{array}$ & $\begin{array}{c}\text { Reduction } \\
\text { Value (\%) }\end{array}$ \\
\hline Roll Former & 0,478 & 0,435 & 8,996 \\
\hline Mosfet & 0,959 & 0,750 & 21,794 \\
\hline
\end{tabular}

\begin{tabular}{|c|c|c|c|}
\hline IGBT & 0,951 & 0,397 & 58,254 \\
\hline V-Block & 0,249 & 0,034 & 86,345 \\
\hline $\begin{array}{l}\text { Bearing } \\
\text { Bushing }\end{array}$ & 0,079 & 0,071 & 10,127 \\
\hline \multicolumn{2}{|c|}{ Average Reduction of Downtime } & 37,103 \\
\hline
\end{tabular}

The value of downtime above is obtained from the calculation of the Minimum Total Downtime. In Table 5 above, it is seen that there is a significant decrease in downtime (average of $37.103 \%$ ) with the implementation of the proposed maintenance system using the RCM method.

\section{Conclusion}

The application of the Reliability Centered Maintenance method shows a decrease in machine downtime. In the application of the FMEA method to identify the risk of failure, it is continued with the RCM method as a new maintenance method, so that there is an average potential reduction in downtime of $37,103 \%$, and an increase in reliability.

\section{Acknowledgement}

North Sumatera University has provided financial support to publish this paper. The author is grateful for the help and support so that this paper has been completed and published.

\section{References}

1. S. Butdee T. Kullawong, Int. J. Appl. Sci. Technol 8(2) (2015)

2. P.L. Ramos, D.C. NAscimento, C. Cocolo, M.J. Nicola, C. Alonso, L.G. Ribeiro, A. Ennes, F. Louzada, Modelling and Simulation in Engineering (2018)

3. S. Supsomboon, K. hongthanapach, Modelling and Simulation in Engineering (2014)

4. M. Dixey, Professional Engineering 6(6) (1993)

5. I. H. Afefy, Engineering 2 (2010)

6. B. Yssaad, Reliability Centered Maintenance Optimization for Power Distribution Systems, University Center of Relizane, Algeria (2009)

7. Rao, Preventive Maintenance Characteristics towards Optimal Maintenance Performance: A Case study of Office Buildings, University of Malaya, Kuala Lumpur (2014)

8. G. Gupta, R.P. Mishra, P. Singhvi, International Journal of Reliability, Quality, and Safety Engineering 23(6) (2016)

9. S. Okwuobi, F. Ishola, O. Ajayi, E. Salawu, A. Aworinde, O. Olatunji, S.A. Akinlabi, Machine

10. M.A. Tarar, International Journal of Industrial Engineering Research and Development 5 (2014)

11. A. Smith, Reliability Centered Maintenance, McGraw-Hill Inc, USA (1993) 